\title{
Clinical Study \\ Risk Factors of Hypertension at UNRWA Primary Health Care Centers in Gaza Governorates
}

\author{
Y. Abed ${ }^{1}$ and S. Abu-Haddaf ${ }^{2}$ \\ ${ }^{1}$ School of Public Health, Al-Quds University, Jeruslem, Palestine \\ ${ }^{2}$ Quality Control Department, Palestinian Ministry of Health, Gaza, Palestine \\ Correspondence should be addressed to S. Abu-Haddaf; seham.pharm@hotmail.com
}

Received 4 January 2013; Accepted 30 January 2013

Academic Editors: C. Szmaragd and J. W. R. Twisk

Copyright (C) 2013 Y. Abed and S. Abu-Haddaf. This is an open access article distributed under the Creative Commons Attribution License, which permits unrestricted use, distribution, and reproduction in any medium, provided the original work is properly cited.

\begin{abstract}
Universally, hypertension is a major public health problem. Identification of risk factors for hypertension supports intervention policies to minimize the disease morbidity and mortality. The main objective is to fill a gap in research literature by establishing baseline information for hypertension risk factors among Palestinians. Methods. A case control study was conducted at UNRWA health care services in Gaza Strip. A proportional systematic random sample of 120 cases matched with sex, and locality to 120 controls were chosen. Data was collected using a questionnaire which included socio-demographic data, lifestyle, and health profile. Collected data was analyzed using SPSS V13. Results. The most common modifiable risk factors of hypertension were physical inactivity (76.7\% versus $15.9 \%)$, obesity ( $67.5 \%$ versus $29.2 \%)$, diabetes mellitus (19.2\% versus $7.5 \%)$, and ex-smoking (15.5\% versus $1 \%)$. Cases and controls show statistical significant differences in values for the lipid profile. Hypertension was significantly associated with low socio economic status, education, and employment. The most common non-modifiable risk factors were age, and family history $(85.8 \%$ versus $71.7 \%)$. Multiple logistic analysis controlling for age showed that significant predictors of hypertension were obesity, physical inactivity, low monthly income and family history. Conclusion. Most of the identified hypertension risk factors are preventable.
\end{abstract}

\section{Introduction}

The rapid rise of noncommunicable diseases (NCDs) represents one of the major health challenges to global development in this century. This growing challenge threatens economic and social development as well as the lives and health of millions of people [1].

Cardiovascular disease (CVD) is the most important cause of NCDs. Hypertension is a major risk factor for CVDs, kidney disease, and other complications. It is a major contributor to premature deaths. Globally, $51 \%$ of stroke and $45 \%$ of ischemic heart disease (IHD) deaths are attributable to high systolic blood pressure [2]. There are one billion hypertensive cases, and four million people die annually as a direct result of hypertension [3]. Additionally, in the Eastern Mediterranean Region (EMR), cardiovascular diseases and stroke account for $31 \%$ of deaths, and hypertension currently affects $26 \%$ of the adult population in the Region [4].
Hypertension disease is a silent killer, and many people with hypertension are not aware that they have the condition [5]. Hypertension disease is influenced by many risk factors, which are connected to the lifestyle [2]. Global modifiable risk factors of hypertension are either preventable or controllable either by health education or health promotion programs. Identifying risk factors for hypertension leads to specific preventive interventions that are favorably affect public health in all countries.

In Palestine, hypertension related disease becomes one of the major health problems. It is the eighth leading cause of death among Palestinians in 2005 [6]. Adult and geriatrics are most vulnerable to risks of hypertension and need more care to prevent the development of hypertension. Socioeconomic changes in our regions lead to major changes in lifestyle towards sedentary lifestyle and increase the incidence and morbidity of this disease. In Gaza Strip (GS), there is little published information on the hypertension disease risk 
factors among the Palestinian population. Therefore, this study may highlight the problem as a public in nature that need community-based intervention programs integrated with health education programs.

UNRWA (the United Nation Relief and Works Agency sector) continued to be the main comprehensive primary health care (PHC) provider for Palestinian Refugees in the Near East. UNRWA operates 137 PHCs scattered in Palestine [7]. UNRWA treated approximately 34,000 hypertensive and 23,000 diabetic patients in GS, with a prevalence rate of $17 \%$ and $12 \%$, respectively, of adult population [8].

\section{Methods}

This is a case-control PHC-based study is covering the main UNRWA centers in the NCDs services, in the five Gaza Governorates for cases and controls selection. One clinic was selected from each different level in each different geographical area to reflect representative sample.

2.1. Study Population. Sample frame consists of all patients diagnosed as having hypertension $(\mathrm{BP} \geq 140 / 90)$ and attending services during the years 2009-2011. Patients are aged 30 years and more from both genders and selected randomly from NCDs services of the UNRWA health care. A further same number of controls were chosen from the same medical centers who seeking other services and proved to be free from hypertension. Controls were matched with cases for gender and place of residency.

2.2. Sample Size. The researcher used Epidemiological Information Program (Epi-info) to calculate the sample size at $95 \%$ CI with power $80 \%$ and based on-one-to one case to control ratio. The total number of proportional systematic random samples is composed of 206 subjects. To overcome nonrespondents, the researcher decided to take 240 persons, divided into 120 cases and 120 controls.

2.3. Sample Process. UNRWA health centers were divided into two categories (large and small) according to the number of services provided and catchment area. GS is divided into five strata as follow: North, Gaza, Midzone, Khan Younis, and Rafah. The researcher chose three large and two small UNRWA clinics from different governorates by using proportional stratified random selection. Proportional sample was used to select the number of cases and controls from each governorate to ensure that the sample is geographically representative.

2.4. Data Collection. Data was collected in randomized manner using a self-constructed face-to-face interviewed questionnaire, which included demographic, socioeconomic, lifestyle, and health profile. Anthropometric measurement, physical examination (BP), and lab test were abstracted from the patient's file. The questionnaire was well prepared after reviewing studies related to the subject. The validity of the questionnaire has been examined by sending the constructed questionnaire with enclosed covering letter about the objective of the study to 10 experts working in the different health fields in order to give their views on the questionnaire. The questionnaire was translated into Arabic by a team of physicians and was back translated to ensure the accuracy of translation. Arabic instrument was pretested on 20 eligible respondents for wording and understanding of the questions, and necessary adjustments were made in the instrument. Data was collected by the researcher and one assistant who trained well to interview the participants and fill the questionnaire.

2.5. Blood Pressure Measurement. For all subjects, their BP was measured to the nearest $2 \mathrm{mmHg}$ in the right arm after a 5-minute rest in a sitting position by a single mercury sphygmomanometer by a well-trained practical nurse and followed up by staff nurse and medical officers. The criteria for the diagnosis of risk factors and hypertension were based on WHO criteria. Hypertension was diagnosed in presence of $\mathrm{BP} \geq 140 / 90 \mathrm{mmHg}$. Risk factors such as smoking, obesity, and hypercholesterolemia were identified.

2.6. Data Management and Statistical Analysis. The quantitative data was analyzed using Statistical Package for Social Sciences (SPSS) program version 13.0. The analyses of data to be conducted were reviewing the filled questionnaire, coding the questions, data double entry, defining and coding the variables, and data cleaning. Frequency tables of all the variables and cross tabulation of the results were done. Odds ratio, 95\% confidence interval, and chi-square test are statistical tools of measurement of association. The statistical level of significance is $P \leq 0.05$. Logistic regression is used to control for age as a confounder.

2.7. Ethical and Administrative Considerations. An academic approval was obtained from School of Public Health at AlQuds University, and an ethical approval was obtained from Helsinki Committee in Gaza to carry out the study. An administrative approval was obtained from UNRWA Chief Field Health Program-Gaza field to conduct the study at UNRWA PHCs. Every participant was provided with a full explanatory form attached to questionnaire included the purpose of the study, assurance about the confidentiality of the information, the instructions how to respond to the questionnaire, and a statement indicating that the participation is voluntary. Honesty was maintained during reporting and analysis of the data with respect to confidentiality and respecting of results.

\section{Results}

Our analysis is based on a sample of 240 persons; 120 cases from both genders matched with sex and place of residency to same number of controls. The finding based on (240) questionnaires, with response rate of $97.5 \%$ for both cases and controls. The nonrespondents were replaced.

3.1. Sociodemographic Characteristics of the Study Population (Table 1). Table one compares the 120 cases with the 120 
TABLE 1: Summary table of sociodemographic characteristics of the study population.

\begin{tabular}{|c|c|c|c|c|c|c|}
\hline \multirow{2}{*}{ Variable } & \multicolumn{2}{|c|}{ Cases } & \multicolumn{2}{|c|}{ Controls } & \multirow{2}{*}{ OR $(95 \% \mathrm{CI})$} & \multirow{2}{*}{$P$ value } \\
\hline & Number & $\%$ & Number & $\%$ & & \\
\hline Sex & & & & & * & * \\
\hline Male & 40 & 33.3 & 40 & 33.3 & & \\
\hline Female & 80 & 66.7 & 80 & 66.7 & & \\
\hline Residency & & & & & * & \\
\hline North & 23 & 19.1 & 23 & 19.1 & & \\
\hline Gaza & 42 & 35 & 42 & 35 & & \\
\hline Midzone & 17 & 14.2 & 17 & 14.2 & & \\
\hline Khan Younis & 23 & 19.2 & 23 & 19.2 & & \\
\hline Rafah & 15 & 12.5 & 15 & 12.5 & & \\
\hline Age (years) & & & & & & 0.023 \\
\hline$<40$ & 24 & 20 & 36 & 30 & 1 & \\
\hline $40-49$ & 28 & 23.3 & 37 & 30.8 & $1.14(0.52-2.46)$ & \\
\hline $50+$ & 68 & 56.7 & 47 & 39.2 & $2.17(1.10-4.32)$ & \\
\hline Education & & & & & & 0.000 \\
\hline Low level & 74 & 61.7 & 32 & 26.6 & $5.93(3.00-11.82)$ & \\
\hline Medium level & 23 & 19.2 & 29 & 24.2 & $2.03(0.92-4.50)$ & \\
\hline High level & 23 & 19.1 & 59 & 49.2 & 1 & \\
\hline Occupation & & & & & & 0.000 \\
\hline Employed & 20 & 16.7 & 60 & 50 & $5(2.64-9.35)$ & \\
\hline Unemployed & 100 & 83.3 & 60 & 50 & & \\
\hline Household income & & & & & & 0.000 \\
\hline$<1700$ NIS & 91 & 75.8 & 41 & 34.2 & 7.15 (3.59-14.39) & \\
\hline $1700-2200$ NIS & 11 & 9.2 & 21 & 17.5 & $1.69(0.62-4.55)$ & \\
\hline$>2200$ NIS & 18 & 15 & 58 & 48.3 & 1 & \\
\hline Marital status & & & & & & 0.218 \\
\hline Single & 5 & 4.1 & 7 & 5.8 & 1 & \\
\hline Married & 98 & 81.7 & 105 & 87.5 & $1.31(0.36-4.93)$ & \\
\hline Widow & 15 & 12.5 & 6 & 5 & $3.50(0.63-20.69)$ & \\
\hline Divorced & 2 & 1.7 & 2 & 1.7 & $1.40(0.09-22.68)$ & \\
\hline
\end{tabular}

${ }^{*}$ Matched variables.

controls matched with sex and locality. Among the selected cases, women have a greater risk of hypertension $(66.7 \%)$ than men $(33.3 \%)$. There were also regional differences in cases, where the highest prevalence was in Gaza city (35\%) and the lowest percentage was in Rafah (12.5\%). This distribution is corresponding to the population differences in the Governorates, where one-third of the population is living in Gaza city. Hypertension disease increases continually with age. Older generations tend to show hypertension more frequently than younger ones. Nearly $56.7 \%$ of all hypertension cases compared with $39.2 \%$ of controls occur between the older age group (50-81 years). The age differences were statistically significant $(P=0.023)$, and marked difference was observed between the younger and the older age groups OR $=2.17$ (1.10-4.32).

Since age could cofound the relationship between the disease and number of the study variables, age adjusted OR is calculated for diabetes, body mass index, physical activity, and lipid profile. Low socioeconomic status is associated with the occurrence of the hypertension. The present study showed highest risk of hypertension among subjects with highest poverty rate with $75.8 \%$ among cases compared to $34.2 \%$ among controls with statistical significant differences OR $=7.15$ (3.59-14.39). The prevalence of hypertension was higher in low educational level with $61.7 \%$ among cases and only $26.6 \%$ among controls. The difference between low and high education is statistically significant with $\mathrm{OR}=5.93$ (3.0-11.82). Unemployed subject was $83.3 \%$ among cases and $50 \%$ among controls with OR $=5$ (2.64-9.35). The burden of hypertension was insignificantly lower among married subjects that could be referred to age variation.

3.2. Health Status Indicators among the Study Population (Table 2). Among cases, 99.2\% reported that they are using pills to control their BP. About $42.8 \%$ take only one drug; out of them $50.98 \%$ take angiotensin converting enzyme inhibitor (ACEI), 15.7\% take diuretic alone, 23.5\% using B-blocker, $5.9 \%$ take centrally acting drug, and $3.92 \%$ received cachannel blockers, while $57.2 \%$ taking more than one drug to control their BP. The compliance among hypertensives was only $29.2 \%$. The percentage of control of BP was only $17.5 \%$. 
TABLE 2: Health status indicators among the study population.

\begin{tabular}{|c|c|c|c|c|c|c|}
\hline \multirow{2}{*}{ Variable } & \multicolumn{2}{|c|}{ Cases } & \multicolumn{2}{|c|}{ Controls } & \multirow{2}{*}{ OR $(95 \% \mathrm{CI})$} & \multirow{2}{*}{$P$ value } \\
\hline & Number & $\%$ & Number & $\%$ & & \\
\hline $\mathrm{BMI} \geq 30 \mathrm{~kg} / \mathrm{m}^{2}$ & 81 & 67.5 & 35 & 29.2 & & \\
\hline $\mathrm{BMI}<30 \mathrm{~kg} / \mathrm{m}^{2}$ & 39 & 32.5 & 85 & 70.8 & $5.04^{*}(2.81-9.08)$ & 0.000 \\
\hline Total & 120 & 100 & 120 & 100 & & \\
\hline Positive family history & 103 & 85.8 & 86 & 71.7 & & \\
\hline Negative family history & 17 & 14.2 & 34 & 28.3 & $2.40(1.20-4.83)$ & 0.007 \\
\hline Total & 120 & 100 & 120 & 100 & & \\
\hline Positive history of DM & 23 & 19.2 & 9 & 7.5 & & \\
\hline Negative history of DM & 97 & 80.8 & 111 & 92.5 & $2.92^{* *}(1.22-7.19)$ & 0.008 \\
\hline Total & 120 & 100 & 120 & 100 & & \\
\hline $\mathrm{TC}<200 \mathrm{mg} / \mathrm{dL}$ & 85 & 70.8 & 100 & 91.7 & & \\
\hline $\mathrm{TC} 200 \mathrm{mg} / \mathrm{dL}+$ & 35 & 29.2 & 9 & 8.3 & $4.58^{* * *}(1.97-10.9)$ & 0.000 \\
\hline Total & 120 & 100 & 109 & 100 & & \\
\hline $\mathrm{LDL}<130 \mathrm{mg} / \mathrm{dL}$ & 87 & 75.7 & 99 & 91.6 & & \\
\hline $\mathrm{LDL} 130 \mathrm{mg} / \mathrm{dL}+$ & 28 & 24.3 & 9 & 8.4 & $3.54^{* * * *}(1.5-8.59)$ & 0.000 \\
\hline Total & 115 & 100 & 108 & 100 & & \\
\hline High $\mathrm{HDL} \geq 40 \mathrm{mg} / \mathrm{dL}$ & 71 & 61.7 & 107 & 99.1 & & \\
\hline Low $\mathrm{HDL}<40 \mathrm{mg} / \mathrm{dL}$ & 44 & 38.3 & 1 & 0.9 & & 0.000 \\
\hline Total & 115 & 100 & 108 & 100 & & \\
\hline $\mathrm{TG}<150 \mathrm{mg} / \mathrm{dL}$ & 77 & 64.7 & 103 & 95.3 & & \\
\hline TG $150 \mathrm{mg} / \mathrm{dL}+$ & 42 & 35.3 & 5 & 4.7 & $11.77^{* * * * *}(4.21-35.5)$ & 0.000 \\
\hline Total & 119 & 100 & 108 & 100 & & \\
\hline
\end{tabular}

Age adjusted OR: ${ }^{*} 5.08$ (2.92-8.85), ${ }^{* *} 2.62$ (1.14-6.0), ${ }^{* * *} 4.3$ (1.95-9.50), ${ }^{* * * *} 3.36$ (1.50-7.45), and ${ }^{* * * * *} 10.92(4.12-28.98)$.

Hypertension was significantly higher in subjects who were diabetic $(\mathrm{OR}=2.92)$, with higher body mass index $(\mathrm{OR}=5.04)$, hypercholesterotemic $(\mathrm{OR}=4.58)$, and with positive family history of hypertension $(\mathrm{OR}=2.4)$. HDL-c was negative and statistically significant associated with the development of hypertension $(\mathrm{OR}=11.77)$, so it is considered a protective factor for hypertension disease. Age adjustment for the OR kept the same relation between hypertension and the lipid profile, diabetes mellitus, and BMI.

3.3. Lifestyle Factors among the Study Population (Table 3). Hypertension was significantly higher in subjects who were ex-smoking, among those exposed to smoking and physically inactive persons. Physical inactivity is much higher among cases $(76.7 \%)$ compared to controls (15.9\%). This association reached statistically significant level $(\mathrm{OR}=17.47)$. Since physical activity could be influenced by age, logistic regression is used to control for age, and the relation between physical inactivity and hypertension kept constant and statistically significant. Hypertension is negatively associated with the current smoking status where the prevalence of current smoking among cases (8.3\%) was lower compared to controls (16.7\%). This is explained by cessation of smoking among the diseased persons. This is true where former smoking was much higher among cases. Additionally, there is positive and statistical significant association between hypertension and passive smoke $(\mathrm{OR}=3.32)$.
3.4. Logistic Regression for the Hypertension Risk Factors (Table 4). Table 4 demonstrates logistic regression analysis for the hypertension risk factors. Significant hypertension predictors as revealed by multivariate logistic regression analysis included physical inactivity, family history of chronic diseases, high BMI, and low family income, remained associated with hypertension, and reached statistically significant level. Blood chemistry variables were not included in the model since they are intervening variables. The association between hypertension and both age and diabetes mellitus did not reach statistically significant level.

\section{Discussion}

The relatively high rate of hypertension among women than men in the present study is matched with many national and international studies showed that men had significantly lower rate of hypertension compared with women [6, 9-14]. In contrast to this, men seem to develop hypertension most often than women among Portuguese adult population [15]. Some studies reported that the rate of hypertension was nearly equal between men and women [16, 17]. These differences may be attributed to differences in age group in these studies, in addition to sociocultural differences or to psychosocial variability.

The result of the present study indicated that hypertension disease increased strongly with age in both sexes, and 
TABLE 3: Lifestyle factors among the study population.

\begin{tabular}{|c|c|c|c|c|c|c|}
\hline \multirow{2}{*}{ Variable } & \multicolumn{2}{|c|}{ Cases } & \multicolumn{2}{|c|}{ Controls } & \multirow{2}{*}{ OR $(95 \% \mathrm{CI})$} & \multirow{2}{*}{$P$ value } \\
\hline & Number & $\%$ & Number & $\%$ & & \\
\hline Physically inactive & 92 & 76.7 & 19 & 15.9 & \multirow{3}{*}{$17.47^{*}(8.74-35.34)$} & \multirow{3}{*}{0.000} \\
\hline Physically active & 28 & 23.3 & 101 & 84.1 & & \\
\hline Total & 120 & 100 & 120 & 100 & & \\
\hline \multicolumn{7}{|l|}{ Current smokers } \\
\hline (i) Yes & 10 & 8.3 & 20 & 16.7 & \multirow{2}{*}{$0.45(0.19-1.0)$} & \multirow{2}{*}{0.05} \\
\hline (ii) No & 110 & 91.7 & 100 & 83.3 & & \\
\hline Former smoker & 17 & 15.5 & 1 & 1 & \multirow{3}{*}{$18.1(2.4-138.7)$} & \multirow{3}{*}{0.000} \\
\hline (i) Stop smoking between 6-12 & 3 & 17.6 & 0 & 0 & & \\
\hline (ii) More than 12 months & 14 & 82.4 & 1 & 100 & & \\
\hline Exposed to others, smoke & 112 & 93.3 & 82 & 68.3 & \multirow{2}{*}{$3.32(1.75-6.30)$} & \multirow{2}{*}{0.001} \\
\hline Not exposed to others, smoke & 8 & 6.7 & 38 & 31.7 & & \\
\hline
\end{tabular}

Age adjusted OR: *17.64 (9.15-33.99).

TABLE 4: Logistic regression for the hypertension risk factors.

\begin{tabular}{lcccccc}
\hline & $B$ & S.E. & Sig. & Odds' ratio & \multicolumn{2}{c}{$95.0 \%$ C.I. for OR } \\
Lower & Upper \\
\hline $\begin{array}{l}\text { Physical } \\
\text { inactivity }\end{array}$ & 2.930 & 0.419 & 0.000 & 18.730 & 8.240 & 42.574 \\
$\begin{array}{l}\text { Family } \\
\text { history }\end{array}$ & 1.468 & 0.498 & 0.003 & 4.343 & 1.636 & 11.529 \\
BMI group & 1.170 & 0.370 & 0.002 & 3.222 & 1.561 & 6.648 \\
Income & 0.602 & 0.215 & 0.005 & 1.826 & 1.198 & 2.781 \\
DM & 0.738 & 0.590 & 0.211 & 2.091 & 0.658 & 6.640 \\
Age group & -0.428 & 0.230 & 0.063 & 0.652 & 0.415 & 1.023 \\
Constant & -8.513 & 1.721 & 0.000 & 0.000 & & \\
\hline
\end{tabular}

getting old is a risk factor for hypertension, as outward symptoms of high BP take a long time to appear. This is in agreement with many studies provided strong relationship between age and hypertension disease [18-23].

This study found statistical significant association between hypertension, occupation, and education statuses. Illiterate and unemployed subjects tended to have significantly higher hypertension prevalence. This may be referring to the impacts of siege and closure after the second Intifada, as a result most of the Palestinian workers in Israeli areas lost their works [24]. Unemployment rate in GS at the end of 2010 was $37.8 \%$ [25], or due to lifelong unhealthy related habits like lack of physical activity due to the majority of illiterates are unemployed, so they sleep more hours, smoking, eating habits, and exposure to stressful events or other lifestyle or may be due to natural setting of the study. This is consistent with some literature and inconsistence with others. Similar surveys reported that hypertension was higher among subjects with lower educational level, retired, and wives engaged in domestic duties [26, 27]. Some studies reported that illiterate and postuniversity educated, unemployed, and subjects doing house duties tended to have significantly higher hypertension [9]. In contrast to this result, some studies found positive and statistical significant association between high educational level and the development of CHD [28].
While other illustrated that the education status affects clients' health, and as much as the level of education increased, the compliance status increased [29]. Other studies showed significant excess risks of hypertension in the subordinate groups compared with managers, blue collar workers, less educated workers, and the older age groups; this association was not significant in women [30]. The total sample in this study is refugee. Comparable with the other findings, the study done among refugees in Jordan, Syrian Arab Republic, Lebanon, GS, and WB illustrated that $9 \%$ of screened people were diagnosed with hypertension and/or diabetes [31]. The researchers concluded that being refugees could be increased the risk of hypertension. This may be due to siege; bad socioeconomic, epidemiological transitions in Palestine, as well as transitions in food consumption patterns and lifestyle have aggravated the burden of poverty-related diseases, as people are suffering from emerging epidemics of NCDs, mainly hypertension.

There were also regional differences in the present study. This is in agreement with the study conducted by Al-Hamdan showed that there were significant regional differences. The highest prevalence was in the central region, and the lowest was in the southern region [9]. Geographical variations in the rate of hypertension were reported in many studies in different regions of the world, which might be related to regional variation in socioeconomic, demographic, and dietary in addition to the geographic characters $[32,33]$. The researchers attributed the highest risk of hypertension in urban population (Gaza city) to environmental factors including large differences in population size, wealth, and health expenditure. In addition, this might be due to economical status, access to the health centers, and the health care system, which is better in Gaza city especially in the centralized areas. Furthermore, the process of urban development and changes in lifestyle and the profile of risk factors like obesity, overweight, hypercholesterolemia, and decrease in physical activity through increasing usage of automated transport and advanced technology at home, consumption of quick meals, and poor quality of food with high saturated fats will also tend to increase the NCDs load. 
The present study showed highest risk of hypertension among subjects who lived under poverty line with significant relationship between BP and subject's monthly income. There is incompatibility between the researchers regarding the association between hypertension and socioeconomic status as income. Some of them showed high BP epidemic among highest poverty rates returning to several confounders associated with hypertension such as tobacco consumption, which is highly prevalent especially among poor. Diet with lower cost and rich in saturated fat, and in simple sugars, with the decreased consumption of fibers, whole grain foods, and complex carbohydrates was more prevalent among people under poverty line. On other hand, other researchers found hypertension common in high-income level referring to consumption of more fast food, soft drink, sweets, and desserts with low physical activity through increased usage of advanced technology. Others showed that low and high incomes may be associated with psychological tensions which may be associated with increased vulnerability of these illness. For example, some studies showed that the income distributions and hypertension were nonlinear indicating elevated levels in low- as well as in high-income groups $[9,34]$. Similarity, other studies indicated that low and high incomes might be associated with psychological tensions, which may be associated with hypertension. Low socioeconomic status is associated with elevated rates of BP-related CVDs [35-37].

The majority of the surveyed adults in this study were married and that support the results of PCBS $\left(2010^{\mathrm{a}}\right)$ about adult people in GS [38], and that is normal because of cultural context of GS as poor households and rural areas, which limit the years of schooling and encourage people to marry from younger ages. The result behind this cultural heritage is to get more children and that cause many problems in the future [39]. Comparable with other finding in the world, hypertension is more common among married than single, widowed, and divorced for both sexes [5, 40, 41].

The study revealed also $99.2 \%$ of the hypertensive patients reported that they are using pills to control their BP; about $42.8 \%$ take only one drug, while $57.2 \%$ were taking more than one drug to control their BP. On another hand, the percentage of uncontrol of BP among cases was $82.5 \%$. Since treatment for hypertension is usually lifelong, the patient and the physician are committed to a long-term association. Treatment should not only aim at lowering BP but should also be integrated into an overall programme of management of associated risk factors and conditions. There is general agreement that five groups of drugs are effective as first-line drugs for the treatment of patients with hypertension [42, 43]. However, the Regional Consultation on Hypertension Management recommended diuretics and B-blockers as the preferred first-line drugs, as they can be successfully used initially in the majority of cases. Combination therapy is usually used when there is no clear response to monotherapy [44]. By comparison with other studies, Kearney et al. mentioned that awareness of hypertension around the world was $46 \%$, and varied from $25.2 \%$ in Korea to $75 \%$ in Barbados. Treatment varied from $10.7 \%$ in Mexico to $66 \%$ in Barbados, and control varied from 5.4\% in Korea to 58\% in Barbados [45]. While Li et al. revealed that only $26.2 \%$ of the population in rural Shandong Province in China, were aware of their hypertension, $22.2 \%$ were currently undergoing antihypertensive treatment, and 3.9\% achieved BP control. Lack of knowledge about hypertension and the importance of $\mathrm{BP}$ control were associated with poor compliance with nonpharmacological and pharmacological treatments [46]. Additionally, Kastarinen et al. revealed that only $68 \%$ of all hypertensive individuals among Finland men and women aged 25-64 years were aware of their condition, among them only 52\% were treated with antihypertensive drugs, and $37 \%$ of the drug treated patients had normal BP [47]. Similarity, Esteghamati et al. illustrated that among hypertensive patients of Iranian adult population aged $25-64$ years, $34 \%$ were aware of their elevated BP, $25 \%$ were taking antihypertensive medications [48].

The most common risk factors identified in this study were lack of physical activity, obesity, family history, high LDL-c $\geq 160 \mathrm{mg} / \mathrm{dL}$, high cholesterol level $\geq 240 \mathrm{mg} / \mathrm{dL}$, smoking, low HDL-c $<40 \mathrm{mg} / \mathrm{dL}$, and high TG level $\geq 200 \mathrm{mg} / \mathrm{dL}$. This is in agreement with many national and international studies which showed that hypertension was higher among participants with one or more of these risk factors $[5,11,12$, $28,40,49-71]$.

The result of this study supports the fact that it is consistent among reviews that hypertension tends to run in families. The high trend of positive family history among the study population may be due to relative marriage contributing to the perpetuation of genetic disorders or adopting of adverse health behaviors like eating habits and smoking that contribute to development of hypertension disease when interacting with a susceptible gene. So genes or behavioring may both be needed for a person to be hypertensive.

Additionally, the chief reason why people with diabetes develop hypertension disease is hardening of the arteries. Diabetes tends to speed up the process of atherosclerosis. The other fact about diabetes is that it affects both large and small blood vessels in the body. Over time, blood vessels become clogged with fatty depots and lose their elasticity.

In addition, people who have high LDL "bad" cholesterol and low HDL "good" cholesterol often have high TG, which can be a sign of carbohydrate sensitivity and insulin resistance.

The majority of the study's results indicated that hypertension disease concentrated among smokers, but interestingly, the majority of former smokers among cases (15.5\%) in the present study were quit smoking within the last 12 months, with positive and statistical significant association between former smokers and the development of hypertension disease $(\mathrm{OR}=18.1, P=0.000)$. This consistent with the study conducted in Iraq by Al-Asadi which found that the percentage of ex-smokers among the hypertensive (11.3\%) was greater than in comparison to controls (3.6\%) [40], and this might be because patients with hypertension recognized the harmful effects of smoking or had been advised by a physician to quit smoking. Additionally, in this study, most of the participants were females (66.7\%). In comparison to men, among cases all women in the present study were nonsmokers. This supports the results of several studies conducted in Palestine which indicated that smoking among 
females is not socially acceptable, or female smoking is underestimated. But the majority of the subjects among cases (93.3\%) exposed to others' smoke. Globally, exposure to passive smoking increases the risk of death from many diseases even for nonsmokers. So there is a need for international harmonization of risk assessment, management practices in a global economy, and a variety of actions and programs to minimize unwarranted environmental tobacco smoking. Public health professionals should work to educate the public on the importance of establishing smoke-free homes and public places for the safety and well being of their children and nonsmoking family members.

\section{Conclusion}

Hypertension poses one of the greatest public health challenges for the 21st century, with particularly alarming trends in several parts of the world. It is considered as the leading cause of death among adults in Palestine, exactly as it is in the whole world. Furthermore, risk factors of hypertension are elements associated with an increased likelihood of this disease. The more risk factors a person has, the greater the vulnerability of having hypertension. The aim of this study is to identify the most common hypertension risk factors among UNRWA primary health care adult registered patients suffering from essential hypertension in GS. The study was conducted to address this information gap. The researcher extracted data on exposures to these selected risk factors from adult Palestinian population and highlight the problem as a public in nature that need community-based intervention programs integrated with health education programs. The study might encourage future national efforts to educate the public about the health risks and might support generation of future hypotheses. It might address the associated and predisposing factors of elevated levels of hypertension, diabetes, hypercholesterolemia, and obesity before starting any public intervention that is targeted to reduce such high prevalence, enhancing the skills of health care providers and equipping health care facilities to provide services related to health promotion, risk detection, and risk reduction. It might support determination of the causes and mechanisms of risk factors, including biologic, social, and epidemiologic and influences effective interventions. Additionally, this study might increase awareness about hypertension among the clients with the identified risk factors in order to decrease morbidity and mortality from this disease.

\section{Acknowledgments}

The authors thank Allah first for helping them every moment and during the study. Thanks and deep respects are due to UNRWA Directors, all doctors, nurses, and technicians in their different positions for agreement for conducting this study through the UNRWA PHCs and considerable help; they provided us while conducting this study. Many thanks go to all those who participated in this study at UNRWA and to all people that have contributed to the completion of this research.

\section{References}

[1] World Health Organization, Proceedings of the 15th Annual Conference of the Indian Society of Hypertension and 4th International CME on Atherosclerosis, Hypertension and Coronary Artery Disease, WHO, New Delhi, India, November 2005.

[2] World Health Organization, "Global health risks," The World Health Report 2004, WHO, 2004.

[3] O. M. N. Khatib and M. S. El-Guindy, Clinical Guideline for the Management of Hypertension, EMRO Technical Publications Series 29, World Health Organization, Cairo, Egypt, 2005.

[4] World Health Organization, Report on the Regional Consultation on Hypertension Prevention and Control (Abu Dhabi, United Arab Emirates 20-22 December), WHO-EM/NCD/042/ E, Regional Office for the Eastern Mediterranean, Cairo, Egypt, 2004.

[5] J. L. Han, "Actions to control hypertension among adults in Oklahoma," Preventing Chronic Disease, vol. 8, no. 1, article A10, 2011.

[6] Ministry of Health, "Health status in Palestine," Annual Report 2004, MOH, Gaza, Palestine, 2005.

[7] UNRWA, "Long and Healthy Lives," 2011, http://www.unrwa .org/userfiles/2010082525837.pdf.

[8] World Health Organization, Gaza Strip Initial Health Needs Assessment, WHO, Gaza, Palestine, 2009.

[9] N. Saeed Al-Hamdan, A. Kutbi, A. A. Choudhry, and R. Nooh, "Characteristics risk factors and treatment practices of known adult hypertensive patients in Saudi Arabia," International Journal of Hypertension, vol. 2010, Article ID 168739, 7 pages, 2010.

[10] M. M. Al-Nozha, M. Abdullah, M. R. Arafah et al., "Hypertension in Saudi Arabia," Saudi Medical Journal, vol. 28, no. 1, pp. 77-84, 2007.

[11] N. Aygül, K. Ozdemir, A. Abaci et al., "Prevalence of risk factors of ST segment elevation myocardial infarction in Turkish Patients living in Central Anatolia," The Anatolian Journal of Cardiology, vol. 9, no. 1, pp. 3-8, 2009.

[12] A. J. Hammoudeh, H. Al-Tarawneh, A. Elharassis et al., "Prevalence of conventional risk factors in Jordanians with coronary heart disease: the Jordan Hyperlipidemia and Related Targets Study (JoHARTS)," International Journal of Cardiology, vol. 110, no. 2, pp. 179-183, 2006.

[13] B. K. Mehra and B. Z. Lashkari, High Blood Pressure: Causes, Prevention and Treatment. A Practical Guide to the Prevention and Control of High Blood Pressure and Its Complications: An Invaluable Source of Information to Help You Stay Healthy and Live Longer, Orient Health Books, Ravindra Press, New Delhi, India, 1992.

[14] Z. Sun, L. Zheng, Y. Wei et al., “The prevalence of prehypertension and hypertension among rural adults in Liaoning province of China," Clinical Cardiology, vol. 30, no. 4, pp. 183-187, 2007.

[15] M. E. Macedo, M. J. Lima, A. O. Silva, P. Alcantara, V. Ramalhinho, and J. Carmona, "Prevalence, awareness, treatment and control of hypertension in Portugal: the PAP study," Journal of Hypertension, vol. 23, no. 9, pp. 1661-1666, 2005.

[16] K. Wilkins, N. R. Campbell, M. R. Joffres et al., "Blood pressure in Canadian adults." Health Reports, vol. 21, no. 1, pp. 37-46, 2010.

[17] Y. Ostchega, S. S. Yoon, J. Hughes, and T. Louis, "Hypertension awareness, treatment, and control-continued disparities in adults: United States, 2005-2006," NCHS Data Brief, no. 3, pp. $1-8,2008$. 
[18] I. Idris, R. Deepa, D. J. Fernando, and V. Mohan, "Relation between age and coronary heart disease (CHD) risk in Asian Indian patients with diabetes: a cross-sectional and prospective cohort study," Diabetes Research and Clinical Practice, vol. 81, no. 2, pp. 243-249, 2008.

[19] W. B. Kannel, "Hypertension and the risk of cardiovascular disease," in Hypertension Pathophysiology, Diagnosis and Management, J. H. Laragh and B. M. Brenner, Eds., pp. 101-117, Raven Press, New York, NY, USA, 1990.

[20] P. M. Kearney, M. Whelton, K. Reynolds, P. Muntner, P. K. Whelton, and J. He, "Global burden of hypertension: analysis of worldwide data," Lancet, vol. 365, no. 9455, pp. 217-223, 2005.

[21] M. Khellah, Assessment of nutritional status among the adult Palestinian aged 19-59 years in the Gaza Strip [M.S. thesis], AlAzhar University, Gaza, Palestine, 2010.

[22] Z. Rionda and A. Clements, "The burden of disease in the West Bank and Gaza," An Assessment Report, The United States Agency for International Development in the West Bank and Gaza, 2000.

[23] M. Wolz, J. Cutler, E. J. Roccella, F. Rohde, T. Thom, and V. Burt, "Statement from the national high blood pressure education program: prevalence of hypertension," American Journal of Hypertension, vol. 13, no. 1, part 1, pp. 103-104, 2000.

[24] Palestinian Central Bureau of Statistics, Press Release: Poverty and Living Conditions in the Palestinian Territory, 2009-2010, PCBS, Ramallah, Palestine, 2010.

[25] Palestinian Center Bureau of Statistics, Palestine in Figures 2010, PCBS, Ramallah, Palestine, 2011.

[26] M. Al-Farsi, M. El-Melighy, S. M. Mohamed, and L. Ali, "Healthy lifestyle study: assessment of life style risk factors among Sur city population," Sur Healthy City Project, 2006 Steps Report Oman, 2011, http://www.who.int/chp/steps/ STEPS_Report_Oman2006.pdf.

[27] M. M. Ibrahim, “The Egyptian National Hypertension Project (NHP): preliminary results," Journal of Human Hypertension, vol. 10, no. 1, pp. S39-S41, 1996.

[28] H. El-Dabbakeh, Coronary heart disease risk factors assessment among adult population in Gaza Strip: hospital based casecontrol study [M.S. thesis], Al-Quds University, Gaza, Palestine, 2000.

[29] M. Reziq, Compliance of hypertensive patients with their management regime at Gaza Strip [M.S. thesis], Al-Quds University, Gaza, Palestine, 2006.

[30] A. Tsutsumi, K. Kayaba, K. Tsutsumi, and M. Igarashi, "Association between job strain and prevalence of hypertension: a cross sectional analysis in a Japanese working population with a wide range of occupations: the Jichi Medical School cohort study," Occupational and Environmental Medicine, vol. 58, no. 6, pp. 367-373, 2001.

[31] H. S. A. Mousa, S. Yousef, F. Riccardo, W. Zeidan, and G. Sabatinelli, "Hyperglycaemia, hypertension and their risk factors among Palestine refugees served by UNRWA," Eastern Mediterranean Health Journal, vol. 16, no. 6, pp. 460-465, 2010.

[32] L. Rampal, S. Rampal, M. Z. Azhar, and A. R. Rahman, "Prevalence, awareness, treatment and control of hypertension in Malaysia: a national study of 16,440 subjects," Public Health, vol. 122, no. 1, pp. 11-18, 2008.

[33] K. Reynolds GU, K. D, and P. Muntneretal, "Geographic variations in the prevalence, awareness, treatment, and control of hypertension in China," Journal of Hypertension, vol. 21, no. 7, pp. 1273-1281, 2003.
[34] M. A. Mendez, R. Cooper, R. Wilks, A. Luke, and T. Forrester, "Income, education, and blood pressure in adults in Jamaica, a middle-income developing country," International Journal of Epidemiology, vol. 32, no. 3, pp. 400-408, 2003.

[35] J. P. Forman, M. J. Stampfer, and G. C. Curhan, "Diet and lifestyle risk factors associated with incident hypertension in women," Journal of the American Medical Association, vol. 302, no. 4, pp. 401-411, 2009.

[36] I. Grotto, M. Huerta, and Y. Sharabi, "Hypertension and socioeconomic status," Current Opinion in Cardiology, vol. 23, no. 4, pp. 335-339, 2008.

[37] K. S. Reddy, D. Prabhakaran, P. Jeemon et al., "Educational status and cardiovascular risk profile in Indians," Proceedings of the National Academy of Sciences of the United States of America, vol. 104, no. 41, pp. 16263-16268, 2007.

[38] Palestinian Central Bureau of Statistics, Palestinians in the End of 2010, PCBS, Ramallah, Palestine, 2010.

[39] B. Mensch, “The transition to marriage," in Growing up Global: The Changing Transition to Adulthood in Developing Countries, C. B. Lloyed, Ed., pp. 416-505, The National Academies Press, Washington, DC, USA, 2005.

[40] J. N. Al-Asadi, "Type A behavior pattern: is it a risk factor for hypertension?" Eastern Mediterranean Health Journal, vol. 16, no. 7, pp. 740-745, 2010.

[41] H. Abu-Tawilla, Patient with acute myocardial infarction: cardiac risk factor profiles, presentation, thrombolytic and outcome [M.S. thesis], Al-Quds University, Gaza, Palestine, 2001.

[42] R. W. Gifford, M. H. Alderman, A. V. Chobanian et al., "The fifth report of the Joint National Committee on Detection, Evaluation, and Treatment of High Blood Pressure (JNC V)," Archives of Internal Medicine, vol. 153, no. 2, pp. 154-183, 1993.

[43] A. Zanchetti, J. Chalmers, K. Arakawa et al., "1993 guidelines for the management of mild hypertension: memorandum from a World Health Organization/International Society of Hypertension meeting," Journal of Hypertension, vol. 11, no. 9, pp. 905918, 1993.

[44] J. Chalmers, "The place of combination therapy in the treatment of hypertension in 1993," Clinical and Experimental Hypertension, vol. 15, no. 6, pp. 1299-1313, 1993.

[45] P. M. Kearney, M. Whelton, K. Reynolds, P. K. Whelton, and J. He, "Worldwide prevalence of hypertension: a systematic review," Journal of Hypertension, vol. 22, no. 1, pp. 11-19, 2004.

[46] H. Li, Q. Meng, X. Sun, A. Salter, N. E. Briggs, and J. E. Hiller, "Prevalence, awareness, treatment, and control of hypertension in rural China: results from Shandong Province," Journal of Hypertension, vol. 28, no. 3, pp. 432-438, 2010.

[47] M. Kastarinen, R. Antikainen, M. Peltonen et al., "Prevalence, awareness and treatment of hypertension in Finland during 1982-2007," Journal of Hypertension, vol. 27, no. 8, pp. 1552-1559, 2009.

[48] A. Esteghamati, M. Abbasi, S. Alikhani et al., "Prevalence, awareness, treatment, and risk factors associated with hypertension in the Iranian population: the national survey of risk factors for noncommunicable diseases of Iran," American Journal of Hypertension, vol. 21, no. 6, pp. 620-626, 2008.

[49] H. Abdeen, "Chronic diseases in Palestine: the rising tide," Bridges Israeli-Palestinian Public Health Magazine, vol. 2, no. 3, 2006.

[50] Abdul-Wahab, A. W. M. Moosa, K. Gharib et al., National Nutrition Survey for Adult Bahrainis Aged 19 Years and above, Ministry of Health, Kingdom of Bahrain, 2002. 
[51] Amy, R. Howard, D. Kathryn, M. Nancy, R. JoAnn E, and E. Julie, "The joint effects of physical activity and body mass index on coronary heart disease risk in women," Archive of Internal Medicine, vol. 168, no. 8, pp. 884-890, 2008.

[52] D. De Bacquer, G. De Backer, D. Cokkinos et al., "Overweight and obesity in patients with established coronary heart disease: are we meeting the challenge?" European Heart Journal, vol. 25, no. 2, pp. 121-128, 2004.

[53] P. Barter, A. M. Gotto, J. C. LaRosa et al., "HDL cholesterol, very low levels of LDL cholesterol, and cardiovascular events," New England Journal of Medicine, vol. 357, no. 13, pp. 1301-1310, 2007.

[54] K. Bibbins-Domingo, P. Coxson, M. J. Pletcher, J. Lightwood, and L. Goldman, "Adolescent overweight and future adult coronary heart disease," New England Journal of Medicine, vol. 357, no. 23, pp. 2371-2379, 2007.

[55] R. Erbel, J. A. C. Delaney, N. Lehmann et al., "Signs of subclinical coronary atherosclerosis in relation to risk factor distribution in the Multi-Ethnic Study of Atherosclerosis (MESA) and the Heinz Nixdorf Recall Study (HNR)," European Heart Journal, vol. 29, no. 22, pp. 2782-2791, 2008.

[56] S. Lamon-Fava, D. M. Herrington, D. M. Reboussin et al., "Plasma levels of HDL subpopulations and remnant lipoproteins predict the extent of angiographically-defined coronary artery disease in postmenopausal women," Arteriosclerosis, Thrombosis, and Vascular Biology, vol. 28, no. 3, pp. 575-579, 2008.

[57] E. Fransson, U. De Faire, A. Ahlbom, C. Reuterwall, J. Hallqvist, and L. Alfredsson, "The effect of leisure-time physical activity on the risk of acute myocardial infarction depending on body mass index: a population-based case-control study," BMC Public Health, vol. 6, article 296, 2006.

[58] R. E. Gilbert, M. Jasik, M. DeLuise, C. J. O'Callaghan, and M. E. Cooper, "Diabetes and hypertension: Australian Diabetes Society position statement," Medical Journal of Australia, vol. 163, no. 7, pp. 372-375, 1995.

[59] S. A. Glantz and W. W. Parmley, "Passive smoking and heart disease: mechanisms and risk," Journal of the American Medical Association, vol. 273, no. 13, pp. 1047-1053, 1995.

[60] Y. He, T. H. Lam, B. Jiang et al., "Passive smoking and risk of peripheral arterial disease and ischemic stroke in chinese women who never smoked," Circulation, vol. 118, no. 15, pp. 1535-1540, 2008.

[61] B. V. Howard, D. C. Robbins, M. L. Sievers et al., "LDL cholesterol as a strong predictor of coronary heart disease in diabetic individuals with insulin resistance and low LDL: the Strong Heart Study," Arteriosclerosis, Thrombosis, and Vascular Biology, vol. 20, no. 3, pp. 830-835, 2000.

[62] B. S. Ibrahim, "The frequency of systolic versus diastolic heart failure in an Egyptian cohort," European Journal of Heart Failure, vol. 5, no. 1, pp. 41-45, 2003.

[63] M. Imazu, H. Yamamoto, M. Toyofuku et al., "Hyperinsulinemia for the development of hypertension: data from the HawaiiLos Angeles-Hiroshima study," Hypertension Research, vol. 24, no. 5, pp. 531-536, 2001.

[64] A. P. Kengne, P. K. Awah, L. Fezeu, and J. C. Mbanya, "The burden of high blood pressure and related risk factors in urban Sub-Saharan Africa: evidences from Douala in Cameroon," African Health Sciences, vol. 7, no. 1, pp. 38-44, 2007.

[65] M. R. Law, J. K. Morris, and N. J. Wald, "Environmental tobacco smoke exposure and ischaemic heart disease: an evaluation of the evidence," British Medical Journal, vol. 315, no. 7114, pp. 973980, 1997.
[66] K. Nasir, E. D. Michos, J. A. Rumberger et al., "Coronary artery calcification and family history of premature coronary heart disease: sibling history is more strongly associated than parental history," Circulation, vol. 110, no. 15, pp. 2150-2156, 2004.

[67] S. Oba, C. Nagata, K. Nakamura, N. Takatsuka, and H. Shimizu, "Self-reported diabetes mellitus and risk of mortality from all causes, cardiovascular disease, and cancer in Takayama: a population-based prospective cohort study in Japan," Journal of Epidemiology, vol. 18, no. 5, pp. 197-203, 2008.

[68] R. Padwal, S. E. Straus, and F. A. McAlister, "Evidence based management of hypertension: cardiovascular risk factors and their effects on the decision to treat hypertension: evidence based review," British Medical Journal, vol. 322, no. 7292, pp. 977-980, 2001.

[69] T. Pischon, C. J. Girman, F. M. Sacks, N. Rifai, M. J. Stampfer, and E. B. Rimm, "Non-high-density lipoprotein cholesterol and apolipoprotein B in the prediction of coronary heart disease in men," Circulation, vol. 112, no. 22, pp. 3375-3383, 2005.

[70] S. Yu, C. C. Patterson, and J. W. G. Yarnell, "Is vigorous physical activity contraindicated in subjects with coronary heart disease? Evidence from the Caerphilly study," European Heart Journal, vol. 29, no. 5, pp. 602-608, 2008.

[71] S. Sieri, V. Krogh, F. Berrino et al., "Dietary glycemic load and index and risk of coronary heart disease in a large Italian cohort: the EPICOR study," Archives of Internal Medicine, vol. 170, no. 7, pp. 640-647, 2010. 


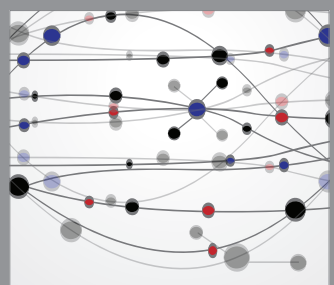

The Scientific World Journal
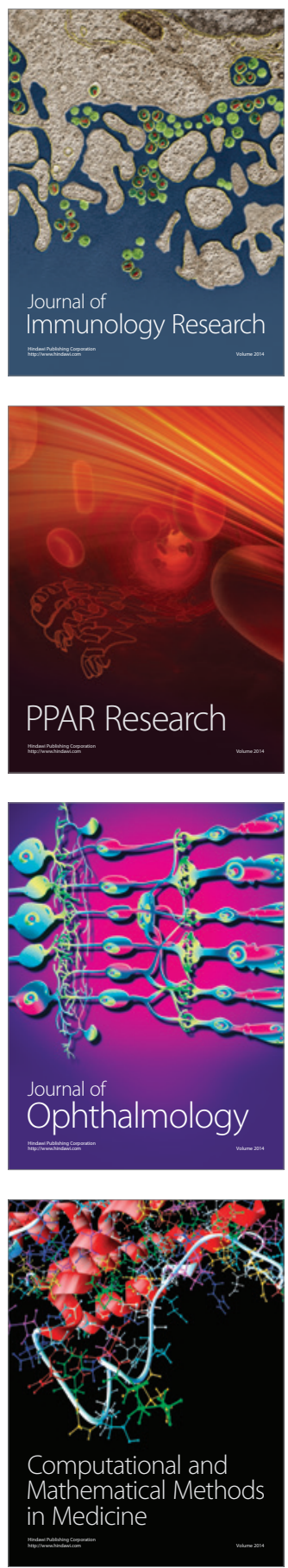

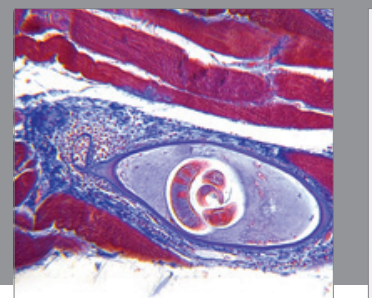

Gastroenterology

Research and Practice
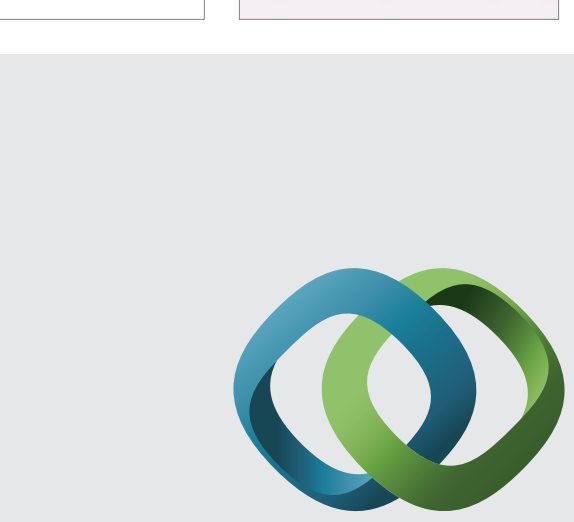

\section{Hindawi}

Submit your manuscripts at

http://www.hindawi.com
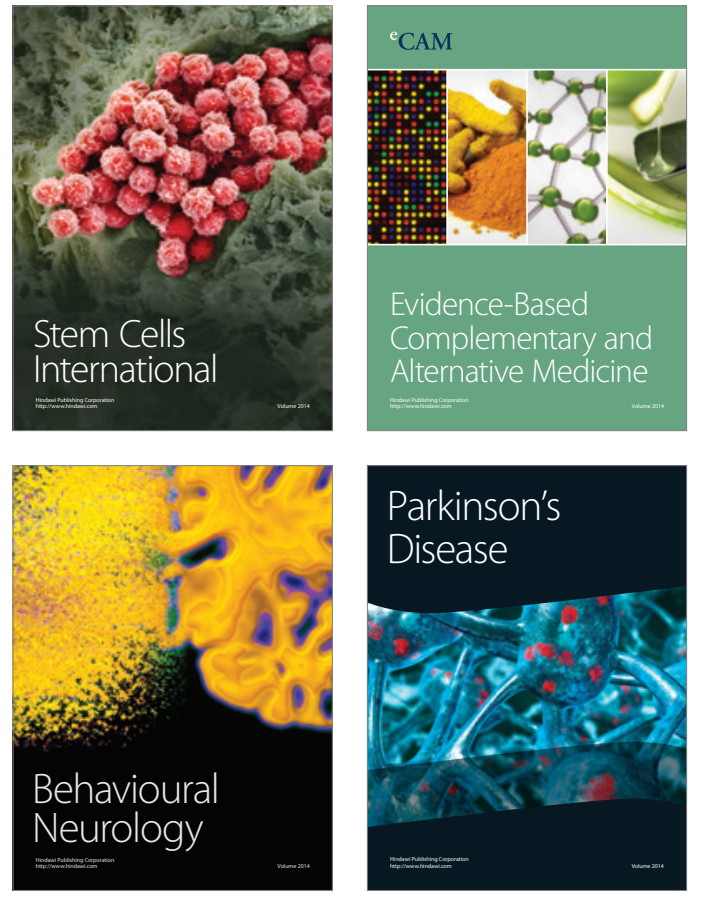
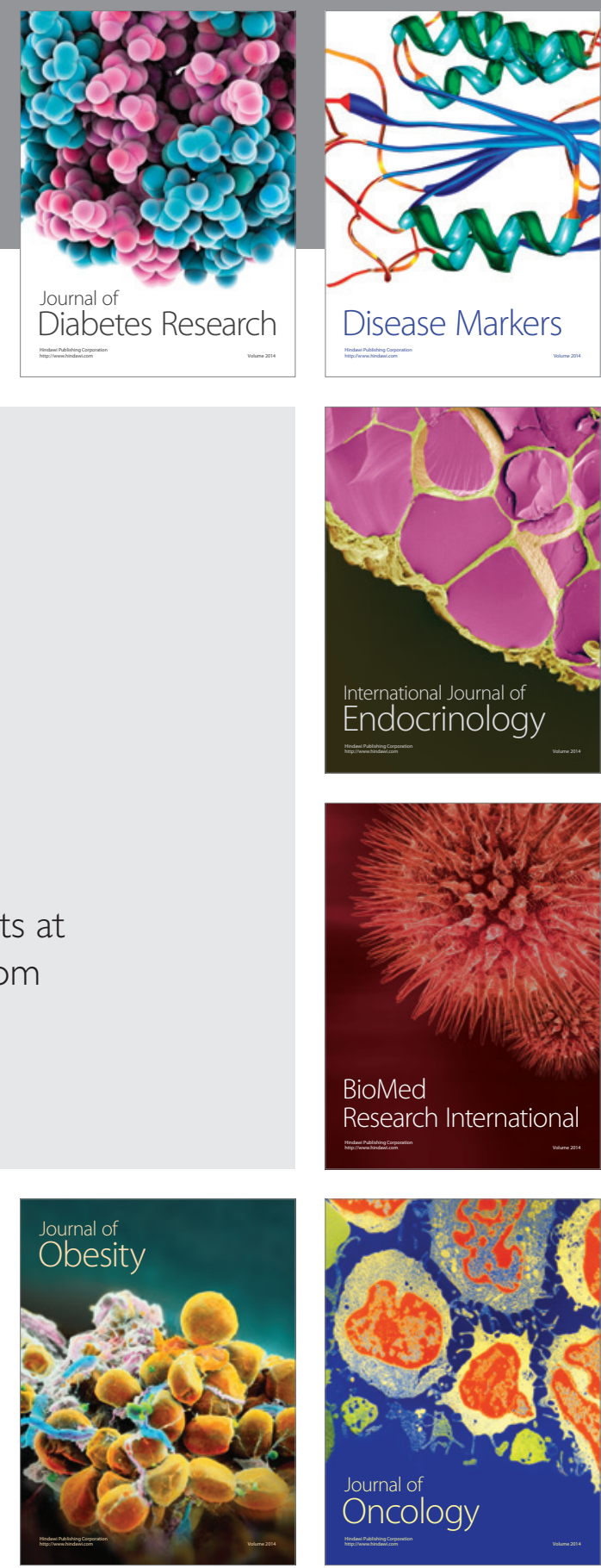

Disease Markers
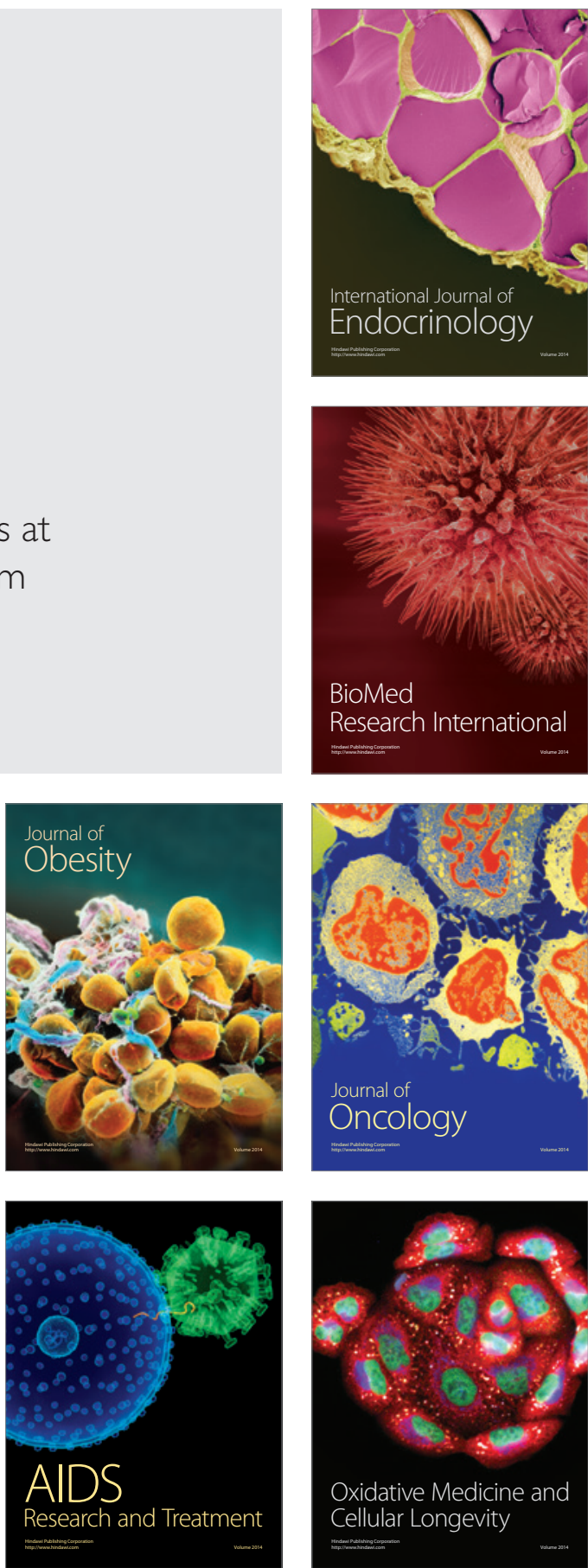